\title{
Automation of Cross-Factory Decision-Making Within Administrative Processes to Enhance Data Quality for Production
}

\author{
Jacob Lohmer ${ }^{1(\bowtie)}\left(\mathbb{D}\right.$, Christian Flechsig ${ }^{1}$, Rainer Lasch $^{1}$, \\ Germar Schneider ${ }^{2}$, Dietrich Eberts ${ }^{2}$, and Benjamin Zettler ${ }^{2}$ \\ ${ }^{1}$ Chair of Business Management, esp. Logistics, \\ Technische Universität Dresden, Dresden, Germany \\ jacob.1ohmer@tu-dresden.de \\ ${ }^{2}$ Infineon Technologies Dresden GmbH \& Co. KG, Dresden, Germany
}

\begin{abstract}
The efforts for digitalization and automation of manufacturing processes led to a neglected increase in manual administrative work tasks. Globalization, diversified supply chains, and the trend towards single-digit lot sizes add further complexity to administrative tasks and render a manual execution ineffective. Automation is a vital step for industries to stay competitive, but the path to it is not trivial. An in-depth analysis, optimization, and reengineering of old process flows is necessary to achieve the full optimization potential of automation activities. In this research, we indicate our approach that uses BPMN to standardize, analyze, and optimize processes from the Line Control department at the semiconductor fab of Infineon Technologies Dresden. Several improvements were proposed and are now at the implementation stage. However, some results are already visible, which we will discuss in the last section. The paper is concluded with limitations and an outlook into further research.
\end{abstract}

Keywords: Digitalization $\cdot$ Process automation $\cdot$ Administrative processes · BPMN $\cdot$ Lot-to-Order matching

\section{Motivation}

The efforts for digitalization in production environments have been considerably increased in the last years. Many manufacturing processes on the shop floor have posed a vital base for optimization and digitalization that enabled semiconductor manufacturers to produce complex products at low costs efficiently. These efforts have led to an increase in administrative back-office activities, which are often repetitive, timeconsuming, and non-value adding (Strykowski and Wojciechowski 2012). Administrative processes have not been examined with the same amount of care and accuracy as production processes. This discrepancy is the result of a more sophisticated measuring process since the output of business processes is more complicated than manufacturing processes and cannot easily be measured by quality and quantity. Scientific methods like Lean Administration are utilized to automate business processes to reduce administrative efforts (Brenner 2018). However, the frequently used scientific methods 
have not been customized to cope with the emerging trend of IoT and Big Data (Janiesch et al. 2017). In this context, an approach to identify and automate repetitive, administrative activities in order to shift the working efforts of the employees towards more innovative tasks would be expedient. Smart collaboration \& knowledge management is a further area of interest.

The activities leading to this contribution are divided into two parts that are aligned and favor each other. On the one hand, we deal with the automation of administrative, manual, and repetitive activities, which we have identified and analyzed in the first place. On the other hand, we are developing a new scientific approach that enables the precise identification, analysis, and optimization of these activities, which can then be automated in a targeted manner. Globalization and diversified supply chains, as well as the trend towards single-digit lot sizes, have increased uncertainty in manufacturing environments and triggered volatile order quantities, especially for semiconductor fabs. Studies predict a further increase in order quantities with small lot sizes, which adds further complexity to the planning processes in semiconductor manufacturing (Mönch et al. 2017). As the usual administrative activities are still performed manually to a certain extent, a change to smaller but accumulating incoming orders is taking full effect at the administrative level. This observation was confirmed in our case study and added further impetus to the iDev40 project and our contribution. In this research, we indicate our approach to handling the increase in administrative activities that uses the Business Process Management and Notation (BPMN) to standardize, analyze and optimize processes from the Line Control department at Infineon Technologies Dresden. Robotic Process Automation (RPA) as a comparatively new method is also part of our approach as RPA can be utilized to automate simple, rule-based tasks without changing the underlying software architecture (Van der Aalst et al. 2018). Several improvements have been proposed and are now at the implementation stage. The results that are already visible will be presented and discussed in this contribution, which is concluded with limitations and an outlook into further research.

\section{Description}

Process management and optimization in business environments are mostly referred to as Business Process Management (BPM). BPM is a systematic approach to capture, design, execute, document, measure, monitor, and control non-automated as well as automated processes. The goal of this approach is always to sustainably achieve the goals that are aligned with the underlying enterprise strategy. BPM aims at identifying and eliminating non-value adding activities as well as the improvement of the process flow. This reduces costs and increases quality (Haddad et al. 2016; Houy et al. 2011). Different life cycle models of BPM have been developed in the literature; we focus on the one by Dumas et al. (2013) which is shown in Fig. 1.

At first, relevant processes are identified and precisely defined. The actual as-is process is then documented and modeled, taking into account the perception and expert knowledge of the concerned employees. The next step, process analysis, then identifies and quantifies issues associated with the as-is process to reveal optimization potential. The processes are redesigned into to-be models and subsequently implemented 


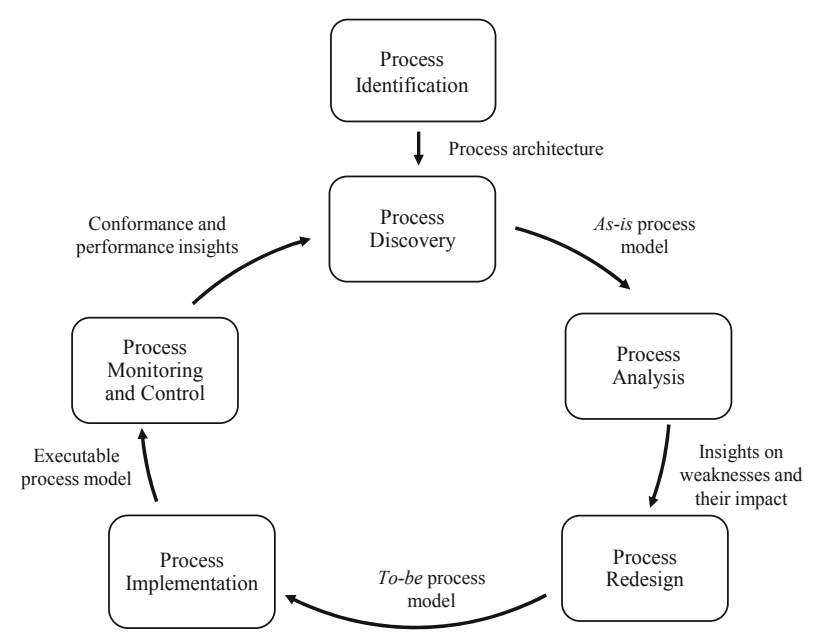

Fig. 1. Lifecycle model of BPM (based on Dumas et al. 2013)

(organizational change management and process automation). Continuous monitoring, analysis, and restarts, if appropriate, complete the BPM life cycle (De Weerdt et al. 2013; Dumas et al. 2013).

Several BPM standards have emerged, the interested reader is referred to Alotaibi and Liu (2017) and Ko et al. (2009) for detailed reviews. We used the renowned Business Process Model and Notation (BPMN), which offers a precise graphical presentation and also provides process execution methods. As one of the semiconductor industry partners in the iDev40 project, Infineon Technologies Dresden has been investigated for areas with potential for improvement regarding administrative, manual and repetitive processes. In particular, one of the central departments of production planning and control internally deals with the automation of existing administrative processes. This department was thoroughly examined, and many processes that could be automated were identified. The first process that is addressed is the allocation procedure of semi-finished products held in the Die Bank area of the semiconductor fab with specific and newly incoming customer orders, see Fig. 2 (based on Guhlich et al. 2015).

The primary step of wafer fabrication in the semiconductor production process is usually executed based on forecasts of customer orders rather than actual customer orders to be able to fulfill demands quickly. After the wafer test and sorting, the fabricated wafer lots are stored in the Die Bank inventory, which functions as the customer order decoupling point in most industry settings, this also applies to our case study. At this point, available lots are allocated to fixed customer orders for the upcoming weeks, a process called lot to order matching. The production mode therefore changes from make to stock setting to make to order setting after the lots are allocated to the customer orders. After lot to order matching, the lots are sent to the backend facility for assembly and test operations and subsequently stored in a finished 

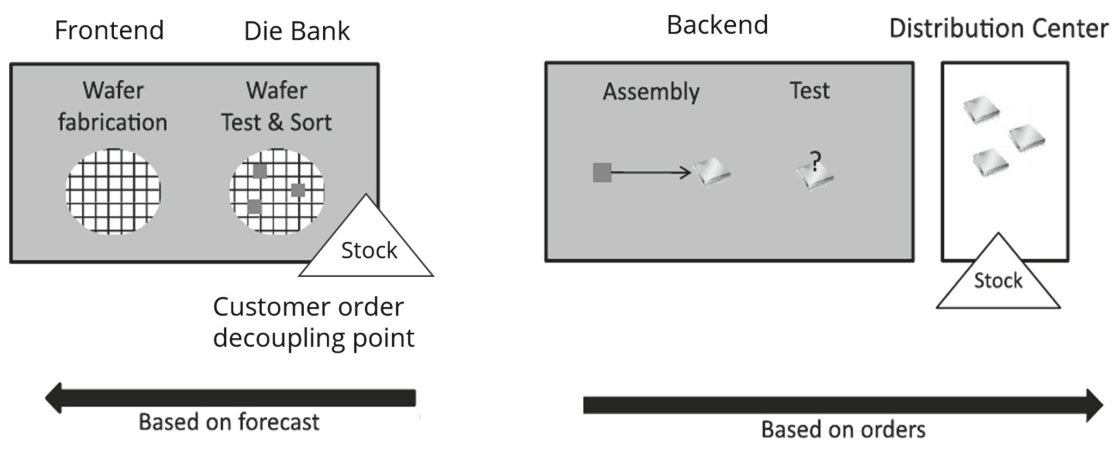

Fig. 2. Semiconductor production process (based on Guhlich et al. 2015)

goods inventory, usually at a distribution center. From the regional distribution centers, the products are distributed to the customer sites.

\section{Results}

The as-is process was analyzed, visualized, and transformed into a business process model using the Business Process Model and Notation (Camunda 2019; OMG 2013). In the as-is process in our case study, the internal process consists of the following steps: The customer demand for the upcoming week is aggregated by the respective product planners in weekly jour fixes and sent as internal orders in several worksheet formats to the colleagues from the line control department. The line control employees then have to apply data extraction and preparation techniques manually. There are several free text fields and different styles, depending on the responsible employee. The customer orders are imported into an MS Access pilot software tool, where the status of the orders is checked. Orders can be new, changed, unchanged, or canceled. The pilot software tool then returns the available lots for each customer order, which are manually allocated to matching customer orders based on a set of criteria that have shown good results in the past but are unable to cope with the upcoming complexity and uncertainty of a growing production site. The start scheduling of fixed customer orders is executed subsequently, where the overall capacity of the fab is estimated based on historical data from the last several weeks, and demand is divided by the number of days available. As the productive planners usually aggregate demands on Thursdays, the capacity of this day of the week is not fully utilized in most weeks. Therefore, this missing capacity is overcompensated on other weekdays (see Fig. 3).

Information was gathered in alignment meetings with several stakeholders regarding the as-is process, perceived shortcomings, and desirable capabilities of the system to be developed. We discovered that the process included many feedback loops and repetitive, unnecessary manual tasks. The BPMN as-is model (see Fig. 4 for an excerpt of the model) has been used in internal feedback rounds to optimize the process on hand and has been verified by internal operators. In the context of the digitalization of business processes, process analysis is indispensable for successful use, because it 


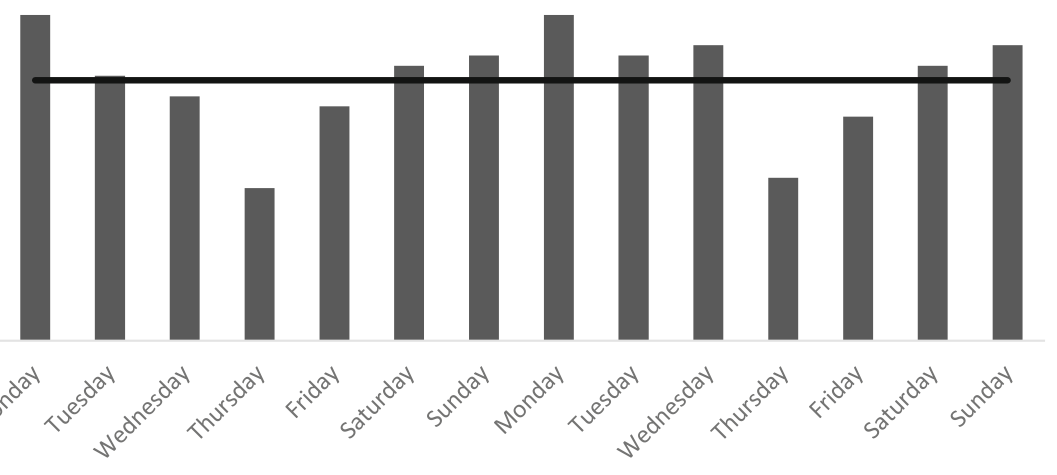

Fig. 3. Wafer starts from the Die bank sorted by weekdays (exemplary representation)

helps to uncover weaknesses and derives further improvement potential, thus paving the way for process automation. Additionally, process optimization is vital for any process that is targeted for automation, as a lack of optimization will complicate digitalization and automation. Optimized processes lead to higher profitability, which then could be further increased by digitalization.

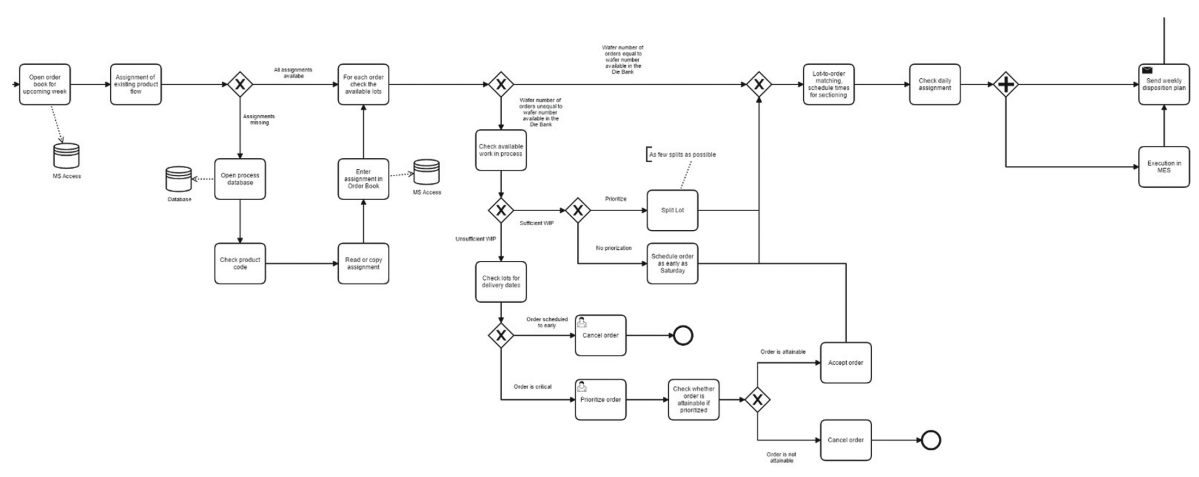

Fig. 4. Excerpt of the BPMN model of the as-is process using the Camunda Modeler (Camunda 2019)

Further interviews were arranged to consider the perspective of all process stakeholders. We have also defined appropriate objectives (e.g., capacity utilization, process efficiency) that can be verified before, during, and after automation. The target procedure for the whole Die Bank Sectioning process is currently in development and will take into account the needs of all process stakeholders and, perspectively, other partners in the supply chain. The roles and responsibilities of all partners within the core process have been defined and can be improved. In areas where full automation is not sufficient, we consider RPA as an alternative solution to perform activities 'bottom-up' 
using existing software tools. An approach to combine RPA and BPM would be helpful in this context, as our recent research has shown. This is also on our agenda for the coming months.

In order to optimize the allocation procedure, we are currently developing a rulebased scheduling system. The system works in real-time (utilizing the existing RealTime Dispatcher repository in the fab) and assigns lots to customer orders based on a set of weighted criteria that is dynamically adjustable to the needs of the supply chain companies. After allocation, the lot starts are scheduled and equally distributed over the weekly time axis. In future research, we aim to include an operational capacity check in the optimization procedure that takes into account the actual uptimes and downtimes of resources.

To consider the scientific state-of-the-art in our system, a literature search was performed for existing literature concerning lot to order matching in semiconductor manufacturing, which returned a small set of articles (Boushell et al. 2008; Carlyle et al. 2001; Fowler et al. 2000; Kim et al. 2008; Knutson et al. 1999; Ng et al. 2010; Sun et al. 2011). The enforcement of a lot integrity policy seems to be the de-facto standard in industrial practice. Each production lot can only be allocated to a single customer order and lot splitting is not allowed (e.g., $\mathrm{Ng}$ et al. 2010). This differs from the industrial setting observed in our study, where the order of small wafer numbers is becoming increasingly popular. Therefore, we decided to incorporate the splitting procedure into the system and also to include the capacity constraints at the sorter resources in our considerations. The lot to order matching algorithm will ideally include a multi-objective optimization and will be designed to be flexible enough to respond adequately to various future requirements.

\section{Discussion and Implications}

The increasing complexity and the small order sizes in modern times have led to a shift of work from production to administration. Several tasks are still executed manually and are error-prone and suboptimal. Automation is essential for the industry to remain competitive, but the road to it is not always clear. In order to achieve the full optimization potential of automation activities, an in-depth analysis, optimization, and reengineering of process flows are essential. In this research, we used BPMN to analyze and optimize the lot to order matching process in the Line Control department of our case partner. Several improvements were proposed and are now at the implementation stage. Although the literature has presented a small set of contributions on the topic of lot to order matching in semiconductor companies, the study of a large semiconductor company has shown that the transfer between science and business is unsatisfying in this context. The process is executed by utilizing the employee's implicit knowledge rather than any sophisticated algorithm.

This study aims at enabling an efficient and time-saving process handling that is adjustable to the needs of the companies involved. Problems might arise as several internal and external partners need to agree on a specific and complicated process definition. The scope of the model might be too broad in some subareas leading to 
time-consuming feedback loops that could limit the achievable outcome. Furthermore, many partners need to be aligned to avoid local optimization and accomplish an overall optimized process.

In future research, we are dealing with the implementation of the developed procedure, test phases, and the productive roll-out. The focus will be on handling development lots to streamline this process and work towards a setup-optimized delivery procedure to optimize a larger share of the process. We also aim at developing a general approach to identify and systematically automate repetitive processes securely. The acquired knowledge from this process automation can be used for this scientific approach.

Acknowledgments. The project iDev40 has received funding from the ECSEL Joint Undertaking under grant agreement No 783163. The JU receives support from the European Union's Horizon 2020 research and innovation programme. It is co-funded by the consortium members, grants from Austria, Germany, Belgium, Italy, Spain and Romania. It is coordinated by Infineon Technologies Austria AG.

\section{References}

Alotaibi, Y., Liu, F.: Survey of business process management: challenges and solutions. Enterp. Inf. Syst. 11, 1119-1153 (2017). https://doi.org/10.1080/17517575.2016.1161238

Boushell, T.G., Fowler, J.W., Keha, A.B., Knutson, K.R., Montgomery, D.C., Boushell, T.G., Fowler, J.W., Keha, A.B., Knutson, K.R.: Evaluation of heuristics for a class-constrained lotto-order matching problem in semiconductor manufacturing. Int. J. Prod. Res. 46, 3143-3166 (2008). https://doi.org/10.1080/00207540601001650

Brenner, J.: Lean Administration. Carl Hanser Verlag, München (2018)

Camunda: Camunda Modeler (2019). https://camunda.com/products/modeler/. Accessed 18 Mar 2019

Carlyle, M., Knutson, K., Fowler, J.: Bin covering algorithms in the second stage of the lot to order matching problem. J. Oper. Res. Soc. 52, 1232-1243 (2001). https://doi.org/10.1057/ palgrave.jors. 2601222

De Weerdt, J., Schupp, A., Vanderloock, A., Baesens, B.: Process mining for the multi-faceted analysis of business processes - a case study in a financial services organization. Comput. Ind. 64, 57-67 (2013). https://doi.org/10.1016/j.compind.2012.09.010

Dumas, M., La Rosa, M., Mendling, J., Reijers, H.A.: Fundamentals of Business Process Management. Springer Verlag, Heidelberg (2013). https://doi.org/10.1007/978-3-642-33143-5

Fowler, J., Knutson, K., Carlyle, M.: Comparison and evaluation of lot-to-order matching policies for a semiconductor assembly and test facility. Int. J. Prod. Res. 38, 1841-1853 (2000). https://doi.org/10.1080/002075400188627

Guhlich, H., Fleischmann, M., Stolletz, R.: Revenue management approach to due date quoting and scheduling in an assemble-to-order production system. OR Spectr. 37, 951-982 (2015). https://doi.org/10.1007/s00291-015-0401-3

Haddad, C., Ayala, D., Uriona Maldonado, M., Forcellini, F.A., Lezana, Á.G.R.: Process improvement for professionalizing non-profit organizations: BPM approach. Bus. Process Manag. J. 22, 634-658 (2016). https://doi.org/10.1108/BPMJ-08-2015-0114 
Houy, C., Fettke, P., Loos, P., Van der Aalst, W.M.P., Krogstie, J.: Business process management in the Large. Bus. Inf. Syst. Eng. 3, 385-388 (2011). https://doi.org/10.1007/ s12599-011-0181-5

Janiesch, C., Koschmider, A., Mecella, M., Weber, B., Burattin, A., Di Ciccio, C., Gal, A., Kannengiesser, U., Mannhardt, F., Mendling, J., Oberweis, A., Reichert, M., Rinderle-Ma, S., Song, W., Su, J., Torres, V., Weidlich, M., Weske, M., Zhang, L.: The internet-of-things meets business process management: mutual benefits and challenges (2017). https://arxiv.org/ abs/1709.03628

Kim, Y., Bang, J., An, K., Lim, S.: A due-date-based algorithm for lot-order assignment in a semiconductor wafer fabrication facility. IEEE Trans. Semicond. Manuf. 21, 209-216 (2008)

Knutson, K., Kempf, K., Fowler, J., Carlyle, M.: Lot-to-order matching for a semiconductor assembly and test facility. IIE Trans. (Inst. Ind. Eng. 31, 1103-1111 (1999). https://doi.org/ 10.1080/07408179908969911

Ko, R.K.L., Lee, S.S.G., Lee, E.W., Wah Lee, E.: Business process management (BPM) standards: a survey. Bus. Process Manag. J. (2009). https://doi.org/10.1108/14637150910987937

Mönch, L., Uzsoy, R., Fowler, J.W.: A survey of semiconductor supply chain models part I: semiconductor supply chains, strategic network design, and supply chain simulation. Int. J. Prod. Res. 7543, 1-20 (2017). https://doi.org/10.1080/00207543.2017.1401234

Ng, T.S., Sun, Y., Fowler, J.: Semiconductor lot allocation using robust optimization. Eur. J. Oper. Res. 205, 557-570 (2010). https://doi.org/10.1016/j.ejor.2010.01.021

OMG: Object Management Group. Business Process Model and Notation (BPMN), version 2.0.2 (2013). http://www.omg.org/spec/BPMN/

Strykowski, S., Wojciechowski, R.: Composable modeling and execution of administrative procedures. In: Kö, A., Leitner, C., Leitold, H., Prosser, A. (eds.) Advancing Democracy, Government and Governance - Lecture Notes in Computer Science, pp. 52-66. Springer Verlag, Berlin/Heidelberg (2012). https://doi.org/10.1007/978-3-642-32701-8

Sun, Y., Fowler, J.W., Shunk, D.L.: Policies for allocating product lots to customer orders in semiconductor manufacturing supply chains. Prod. Plan. Control 22, 69-80 (2011). https:// doi.org/10.1080/09537287.2010.490020

Van der Aalst, W.M.P., Bichler, M., Heinzl, A.: Robotic process automation. Bus. Inf. Syst. Eng. 60, 269-272 (2018). https://doi.org/10.1007/s12599-018-0542-4

Open Access This chapter is licensed under the terms of the Creative Commons Attribution 4.0 International License (http://creativecommons.org/licenses/by/4.0/), which permits use, sharing, adaptation, distribution and reproduction in any medium or format, as long as you give appropriate credit to the original author(s) and the source, provide a link to the Creative Commons license and indicate if changes were made.

The images or other third party material in this chapter are included in the chapter's Creative Commons license, unless indicated otherwise in a credit line to the material. If material is not included in the chapter's Creative Commons license and your intended use is not permitted by statutory regulation or exceeds the permitted use, you will need to obtain permission directly from the copyright holder.

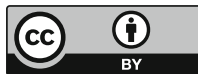

